Available online at https://jurnal.stmikroyal.ac.id/index.php/jurdimas

\title{
PELATIHAN MEMBUAT PROPOSAL PENGAJUAN DANA CSR PERUSAHAAN UNTUK BANTUAN PEMBANGUNAN MUSHOLA AT-TAQWA
}

\author{
Rafika Sari $^{1^{*}}$, Reny Azziatul Febrianti ${ }^{1}$ \\ ${ }^{1}$ Program Studi Akuntansi Universitas Indo Global Mandiri \\ email:*rafikasari@uigm.ac.id
}

\begin{abstract}
The problem that arises in the surrounding community is the lack of information regarding how to obtain funds in terms of village development and nearby places of worship, the condition of the prayer room is quite apprehensive, both the road to the location and the place of ablution, in this case the purpose of this community service is form an organization of holiness. mushola and has the ability to make fundraising proposals for the construction of a prayer room and can support the operational costs of the At-Taqwa. This community service is carried out. methods such as: Percentage, question and answer process so that problems making assistance proposals so that the board members can directly make a proposal and submit it to the party who will be the target. The results of the community service activities included. The training was attended by 20 participants consisting of administrators and residents around the mosque. Participants responded very well to the training and currently the management has been able to make and distribute proposals as an alternative withdrawing company csr funds as assistance in building a prayer room, several companies such as Bank Mandiri, provide funds for the rehabilitation of mosque construction
\end{abstract}

Keywords: fund proposal; mushola; training.

Abstrak: Permasalahan yang timbul dimasyrakat sekitar adalah kurangnaya informasi dalam terhadap bagimana memperloleh dana dalam hal pembangunan desa dan tempat ibadah disekitar, dimana kondisi mushola cukup memprihatinkan baik jalan untuk ke lokasi maupun tempat wudhu dalam hal ini Tujuan dari Pengabdian kepada masyarat ini agar terbentuknya organisasi kepengerusan mushola dan memiliki kemampuan untuk membuat proposal pengalangan dana demi pembangunan mushola dan dapat menunjang biaya operasional mushola At-Taqwa. Pengabdian kepada masyarakat ini dilakukan dengan beberapa metode pengabdian diantaranya: Persentasi, proses tanya jawab agar permasalahan dalam pembuatan proposal pendampingan agar tik pengurus dapat secara langsung membuat proposal dan mengajukanya ke pihak pihak yang akan menjadi target. Hasil dari kegiatan pengabdian pada masyarakat ini antara lain: Pelatihan ini berjalan dengan baik dan sukses para tim pengurus sangat antusias dalam membuat proposal untuk pembangina mushola. Pelatihan dihadiri oleh 20 orang peserta terdiri dari pengurus dan warga sekitar mushola, Peserta merespon pelatihan dengan sangat baik dan saat ini pengurus sudah dapat membuat dan menyalurkan proposal sebagai alternatif dalam menarik dana csr perusahaan sebagai bantuan dalam pembangunan mushola, beberapa perusahaan seperti bank Mandiri, memberikan dana untuk rehab pembangunan mushola

Kata Kunci: mushola; pelatihan; proposal dana. 
Available online at https://jurnal.stmikroyal.ac.id/index.php/jurdimas

\section{PENDAHULUAN}

Mushola At-Taqwa yang bertempat di kelurahan Karang Anyar kecamatan gandus menjadi tempat beribadah dan perkumpulan pengajian bapak ibu didaerah sekitar namun kondisi mushola tersebut masih memprihatinkan di-karenakan masih kesulitan dalam mendapatkan dana untuk rehab bangunan dan menunjang operasional kegiatan, selama ini mushola hanya mengadalkan uang celengan yang bisanya didapatkan dari pengguna namun melihat kondisi bangunan mushola tersebut butuh rehab sehingga tim pengabdian dari universitas niversitas Indo Global Mandiri mengajak bapak ibu pengurus mushola untuk mengadakan pelatihan pembuatan proposal pengalangan dana untuk diajukan sebagai dana Corporate Social Responsibility (CSR) perusahaan sekitar dan membantu menyalurkanya kepada perusahaan perusahaan untuk menarik dana CSR sehingga mushola At-Taqwa dapat merehab bangunan dan membiayai operasional kegiataan mushola. Mushola ini selalu dipakai masyarakat dalam menjalankan ibadah baik sholat berjamaah maupun pengajian, namun dilihat dari fisik mushola tampak perlu direhab dan diperbaiki, serta perlu dana untuk kegiatan operasional mushola perlu diaadakan kegiatan pelatihan agar dapat menarik dana csr dari perusahaan yang ada disekitar kota palembang. Kegiatan pengadian ini diharapkan dapat menjadi program yang mendukung pembangunan masyarakat sekitar khusunya tempat beribadah dalam membangun mushola maupun kegiatanya selain itu pengurus yang memiliki harapan bahwa mushola akan menjadi tempat berkumpul dan beribadah serta silaturahmi warga bisa memiliki bangunan yang lebih layak dan memiliki dana kegiatan sehingga kegiatan mushola dapat berjalan lancar dan baik. Permasalahanya para pengurus dan masyarakat belum memiliki kemampuan dalam membuat proposal pengajuan pengalangan dana permasalahan lainya yaitu pengurus msi binggun bagaimana cara memperoleh dana untuk pembangunan mushola oleh sebab itu perlu diadakan pelatihan bagi pengurus mushola untuk pembuatan proposal pengajuan dana CSR. Hal ini membutuhkan pemahaman baik dalam teori maupun praktik. Agar pengurus mempunyai kemampuan memberdayakan memiliki dana untuk rehap bangunan mushola dan kegiatan-kegiatan ibadah lainya serta dapat mengembangkan potensi dari para pengurus demi kemajuan mushola at-taqwa ini

Perwujutan CSR yang akan dilakukan oleh perusahaan milik negara, swasta maupun pemerintahan biasanya disalurkan dengan nama program kemitran dan bina lingkungan atau (PKBL) ini akan memberikan konstribusi dana dalam mendukung kegitan sosial masyrakat disekitarnya sebagai perwujutan kepedulian kepada masyrakat disekitar. Sebelum megarah ke pada pengabdian ini tim telah mempelajari beberapa hal terkait hal-hal yang dilakukan oleh pemerintaan maupun perusahaan milik negara dalam membentuk kepeduian maupun tanggung jawab sosialnya setiap perusahaan memiliki harapan terwujudnya kepercayaan masyrakat akan berdampak baik bagi peruahaan baik dari segi sosial dan ekonomi. Dapat disimpulkan bahwa perusahaan seharusnya melakukan tanggung jawab sosial dengan fokus dan konsisten dengan didukung oleh strategi yang tepat dengan implementasi yang sesuai dengan standart yang ada, hal tersebut akan terlihat dengan memberikan manfaat dan value bagi 
Available online at https://jurnal.stmikroyal.ac.id/index.php/jurdimas

masyarakat dan menciptakan image yang baik serta akan memberikan kenyamanan dan mengurangi konflen dan konflik dari masyrakat dengan menciptakan lingkungan sosial yang baik, menkonstribusi dana untuk kepentingan masyarakat (Hadi \& Nor, 2011).

Jenis program kemitraan terdiri program peningkatan ekonomi dan pemerdayaan rakyat dengan cara melakukan pengalangan dana bantuan, dana pembangunan, serta pemberian dana bantuan usaha seperti pinjaman dana dan membantu pembangunan tempat ibadah masyarakat disekitar serta demi melakukan pendekatan dengan masyarakat sekitar harus menjadi komitmen yang dipegang oleh perusahaan dalam memenuhi aspek-aspek sosial dan ekonomi terkait perwujudtan tanggung jawab sosial dalam ketelibatan dan upaya peningkatan kesejahteraan masyarakat sekitar dalam kegiatan masyarakat. Halhal seperti ini menjadi perwujutan perusahaan dalam bentuk pensuksesan program bina lingkungan, yaitu program pembinaan masyrakat sekitar (Putri, Sudharma \& Purmosidhi, 2016).

CSR sebagai bentuk perwujutan kerjasama diantara perusahaan (BUMN maupun Swasta) dengan setiap steakholder dimana baik secara langsung ataupun secara tidak langsung berhubungan dengan suatu perusahaan untuk dapat selalu menjamin kesuksesan dan keberlangsungan hidup usahanya (sustainability) dari perusahaan tersebut. Penjelasan dapat diartikan atau menjadi sama dengan Tanggung Jawab Sosial dan Lingkungan, yang dapat diartikan sebagai suatu komitmen dari perusahaan dalam berperan serta berperan serta untuk menwujutkan pembangunan ekonomi masyrakat sekitar secara berkelanjutan sehingga dapat meningkatkan kualitas kehidupan sosial dan lingkungan sekitar yang bermanfaat bagi masyarakat sekitar baik untuk perusahaan perseroan sendiri, kepentingan pihak pihak yang terkait atau disebut steak holder, dan atau masyarakat disekitar pada umumnya (Kurniasari \& Warastuti, 2015).

Terdapat tahapan tahapan dalam melakukan pemberdayaan kepada masyarakat diantaranya dengan memperhatikan status mana masyarakat kurang dalam menunjukan kontribusinya. Terkadang manusia tidak mengerjakan sesuatu dikarenakan kurang memahami apa yang harus dilakukanya dan atau memiliki pemahaman namun tidak memiliki kesadaran untuk melakukan tindakan yang dianggap perlu dilakukan arah terkini akan menjadi focus permasalahan yang akan diselesaikan sesuai dengan arah dan fokusnya (Stacia, 2013) .

Disamping hal lainya adalah ditenukan oleh kemauan dari masyarakat itu sendiri untuk mampu mengupgrade diri demi tercapainya tujuan pembangunan masyarakat yang harus dipenuhi. Untuk itu perlu mensingkronkan antara keinginan akan kepentingan manusia itu sendiri dalam meningkatkan potensi dirinya dan meningkatkan kesejahteraanya sehingga mampu menunjang pembangunan mushola attaqwa dengan kebutuhan pembangunan masyarakat desa dimana mereka menjadi bagian dari pembangunana itu sendiri. sehingga dirasakan perlu untuk menarik dana CSR dari perusahaan agar tercapainya kebutuhan dana untuk kegiatan dan rehap mushola. Untuk itu perlu diadakan pelatihan bagaimana melakukan pengalangan dana untuk memperloleh dana CSR dari perusahaan guna membantu dalam perbaikan atau rehab pembangunan mushola serta membiaya kegiatan mushola. 
Available online at https://jurnal.stmikroyal.ac.id/index.php/jurdimas

\section{METODE}

Metode pelaksanaa kegiatan PKM ini adalah dalam bentuk pelatihan, dengan melakukan pelatihan dengan cara persentasi langkah-langkah pembuatan prosposal pengalangan dana, sesi tanya jawab, dan pendampingan pembuatan proposal pengalangan dana dan tahap evaluasi.

Menurut (Dessler \& Gary, 1997) pelatihan merupakan suatu usaha yang terencana dalam memfasilitasi pembelajaran tentang sesuatu yang berkaitan dengan pengetahuan, keahlian dan perilaku seseorang masyarakat. Pelatihan juga mempunyai pengaruh yang besar bagi pengembangan perusahaan.

Pelatihan mempersiapkan peserta latihan untuk mengambil jalur tindakan tertentu yang dilukiskan oleh teknologi dan organisasi tempat bekerja, dan membantu peserta memperbaiki prestasi dalam kegiatannya terutama mengenai pengertian dan keterampilan (Ataunur \& Ariyanto, 2015). Pelatihan merupakan kegiatan yang melibatkan kegiatan yang disertai dengan pengoperasian dan peralatan yang dibutuhkan (Morelli, 2015).

Sedangkan prosedur tahapan yang akan dilakukan untuk mendukung keberhasilan kegiatan adalah persiapan, pelaksanaan kegiatandan evaluasi dari hasil kegiatan itu sendiri (Aisyah \& Kurniawati, 2019) dilaksanakan di kelurahan Karang Anyar tepatnya pada tanggal 28 Desember 2020 bertempat mushola at taqwa tahapan awal kegiatan dilakukan yaitu mengadakan pertemuan dengan para pengurus mushola dan membahas tentang permasalahan kesulitan dana untuk pembangunan serta kegiatan mushola selanjutnya menetapkan solusi dengan mengadakan pelatihan proposal pengalangan dana CSR perusahaan sekitar serta menyalurkanya agar dapat memperoleh dana dari CSR Perusahaan.

\section{Pelaksanaan Kegiatan}

Kegiatan dalam penyuluhan, pelatihan dan sosoalisasi pengabdian masyarakat ini dikuti oleh 20 orang yang terdiri dari pengurus mushola serta oraganisasi pengajian mushola at taqwa

\section{PEMBAHASAN}

Pelaksanaan kegiatan pelatihan Pembuatan Proposal Pengalangan dana dilakukan dalam masa 3-4 minggu

Kegiatan pada pertama kegiatan survey pendekatan serat pengenalan lingkungan sekitar bersama mahasiswa dan mahasiswi universitas IGM Palembang, minggu kedua melihat situasi dan kondisi serta permasalahan yang ada pada pembangunan mushola at taqwa minggu ketiga melakukan pelatihan bagaimana membuat proposal pengalangan dana ke perusahaan demi menarik dana CSR perusahaan sekitar agar dapat memperoleh dana untuk melakukan rehab bangunan mushola.

Selanjutnya adalah tahap evalusi kemampuan pengurus mushola dalam membuat proposal bisnis. evaluasi merupakanproses yang berfungsi untuk mengetahui dan mengukur hasil dari pembelajaran yang telah dilaksanakan (Wahyuni \& Sutarto, 2018).

Selanjutnya pada minggu keempat membantu melakukan penyaluran proposal kepada perusahaan perusahaan sekitar palembang demi memperoleh dana pembangunan mushola dan diakhir kegitan mushola dapat memperoleh dana bantuan dari beberapa perusahaan dan mulai melakukan pembangunan rehab Mushola, alhamdullilah kegiatan ini 
bermanfaat bagi Masyarakat dan kepengurusan, pengurus dan masyarakat sekitaar mushola.

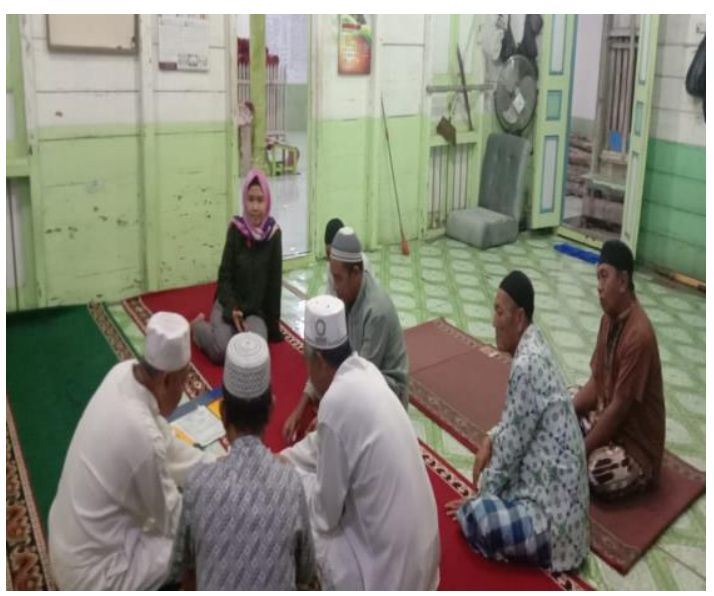

Gambar 1. Pelaksanaan kegiatan berdiskusi permasalahan

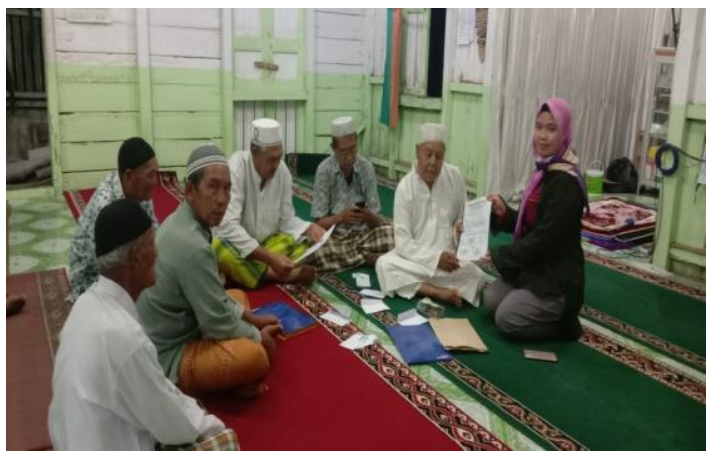

Gambar 2. Pelaksanaan penyerahan proposal dan dana dari beberapa perusahaan

\section{Teknik Pembuatan}

Proposal adalah semua bentuk rancangan kegiatan yang dibuat dalam bentuk formal dan standar (KBBI,1990).

Dalam membuat Proposal pengalangan dana dibutuhkan teknik yang tepat seperti merancang proposal, latar belakang, tujuan, dana yang dibutuhkan, dan arah pengunaan dana

\section{Pengumpulan Data dan Informasi}

Sebelum menyusun proposal, mempersiapkan bahan atau informasi untuk membantu dalam proses perumusan konsep kegiatan.

\section{Penetapan Rencana Program}

Pada poin ini perlu ditegaskan hal hal apa saja yang menjadi point dalam rencana program yang membutuhkan dana dibuat dengan spesifik jelas ringkas dan mudah dipahami.

\section{Pengunaan Bahasa}

Dalam Pengunaan bahasa penting memperhatikan ejaan yang benar, serta tepat pada sasaran dalam tujuan dan tidak berbelit belit.

\section{Penyerahan Proposal Ke perusahaan dan Pihak Pihak Penyalur Dana}

Setelah membuat proposal makan tindakan selanjtnya adalah memberikan atau menyalurkan proposal ke target yang ditujukan untuk memperoleh dana sesuai dengan tujuan yang ada

\section{SIMPULAN}

Kegiatan pengabdian kepda masyarakat ini dilakukan berupa latihan dalam bentuk persentasi pembuatan proposal, tanya jawab serta praktek langsung sehingga permasalahan dan kesulitan tim dapat teratasi

$$
\text { Pengurus mushola dan }
$$
masyarakat sekitar sangat antusias dan mampu membuat proposal pengajuan dana dan memperoleh dana bantuan serta dimulainya pembangunan mushola atau rehab mushola Dengan adanya kegiatan Pengabdian ini dapat terbentuk kepengurusan mushola yang lebih baik, para pengurus mampu melakukan pencairan dana dengan mengajukan proposal penggalangan dana dalam hal ini beberapa perusahaan telah bekerja sama dalam hal pemberian dana untuk 
Available online at https://jurnal.stmikroyal.ac.id/index.php/jurdimas

pembangunan dan operasional kegiatan mushola at taqwa

\section{UCAPAN TERIMA KASIH}

Ucapan terima diberikan kepada Pengurus mushola yang telah mengikuti pelatihan dan berhasil memperoleh dana untuk rehab mushola serta kepada tim dan perusahaan yang telah memberikan dana semoga amal dan ibadah serta tujuan pemberdayaan masyrakat dan lingkungan ini berjalan sesuai dengan yang dimanahkan dan memperoleh ridho allah.

\section{DAFTAR PUSTAKA}

Aisyah, S., \& Kurniati, K. (2019, October). PKM keterampilan menjahit pada remaja putri di Desa Bonto Jai Kecamatan Bissapu Kabupaten Bantaeng. In Seminar Nasional Pengabdian Kepada Masyarakat (Vol. 2019, No. 1).

Ataunur, I., \& Ariyanto, E. (2016). Pengaruh kompetensi dan pelatihan terhadap kinerja karyawan PT. Adaro Energy Tbk. Telaah Bisnis, 16(2).

Dessler \& Gary. (1997). Manajemen Sumberdaya Manusia. Jakarta : PT. Prenhallindo.

Hadi,Nor.2011. Corporate Social Responsibility.Yogyakarta:Grah a Ilmu. (n.d.).

Kamus Besar Bahasa Indonesia, Tim Penyusun Kamus Pusat
Pembinaan Dan Pengembagan Bahasa Departemen Pendidikan dan Kebudayaan,Jakarta: Balai Pustaka, 1990

Kurniasari, W., \& Warastuti, Y. (2015). The relationship between CSR and profitability to firm value in Sri-Kehati Index. Journal of Economic Behaviour, 5(1), 314.

Morelli, N. (2015). Challenges in designing and scaling up community services. The Design Journal, 18(2), 269-290. https://doi.org/doi.org/10.2752/1 75630615X14212498964394

Putri, A. K., Sudarma, M., \& Purnomosidhi, B. (2016). Pengaruh Corporate Social Responsibility terhadap Nilai Perusahaan dengan Ukuran Perusahaan dan Jumlah Dewan Komisaris sebagai Variabel Pemoderasi ( Studi pada Perusahaan Manufaktur yang terdaftar Bursa Efek Indonesia ). Jurnal Aplikasi Manajemen, 344, 1-15.

Stacia, E. (2013). Pengaruh Pengungkapan Corporate Social Responsibility terhadap Nilai Perusahaan di Sektor Pertambangan. Business Accounting Review, 3(2), 81-90. Wahyuni, S., \& Sutarto, J. (2018). Pembelajaran Kursus Menjahit di Lembaga Kursus dan Pelatihan Gassebo Kabupaten Kendal. Jurnal Pendidikan Dan Pemberdayaan Masyarakat, Vol 5. 